\title{
Selective habituation of defensive behavior: Evidence for predator-prey synchrony
}

\author{
CAROLYN ROVEE-COLLIER, JOANN B. CAPATIDES, JEFFREY W. FAGEN, \\ and VAL NEGRI \\ Rutgers University, New Brunswick, New Jersey
}

\begin{abstract}
The selective nocturnal persistence of death feigning, an antipredator behavior, was assessed in four studies involving single daily trials. In Experiments 1 and 2, White Leghorn chicks exhibited a progressive decline in death feigning durations in both the light and the dark phases of their photoperiods over 8 days, but resistance to habituation was greater at night. When nocturnal death feigning was induced to a habituation criterion (Experiment 3), it was extremely persistent and was not completely abolished in some chicks, even after 25 consecutive test days. Because nocturnal response durations of chicks tested cross-sectionally increased over the same developmental period (Experiment 4), a shifting developmental baseline was excluded as the basis for the declining response durations observed in the first three studies. The differential plasticity of death feigning at two times of day is consistent with the argument that predatorprey synchrony confers a selective advantage, and suggests an additional biological constraint on learning.
\end{abstract}

Despite the numerous varieties of animal life and the niches that they occupy, many species make use of highly similar forms of predator defense. One of the most common is death feigning, also described as tonic immobility or animal hypnosis (for reviews, see Gallup, 1974a, 1977). This behavior is induced by a combination of sustained physical restraint and tactile pressure on the neck and upper back following capture and unsuccessful struggle (Ratner, $1967,1975)$. Its efficacy appears to derive from the removal of movement, visual, and possibly thermal cues that trigger appendage-severing or killing by predators and from the subsequent escape opportunities that accompany either momentary release or premature caching (Edmunds, 1974).

Aschoff (1964) has argued that natural selection has favored the synchronization of the defensive behaviors of prey with the feeding activities of their predators. That is, when a given antipredator behavior is most likely to be used, it is also most likely to be strongest and most effective. It follows from this argument that visually based defenses (e.g., vigilance, freezing) should be most prominent during the day and maximally effective against diurnal

This research was supported in part by Grant MH-34125 from the National Institute of Mental Health to the senior author. Portions of the data were presented at the meeting of the Eastern Psychological Association, Boston, March 1977. We thank Sandra Yospe and Lynn W. Kaufman for assistance with the data collection and analysis. Jeffrey $W$. Fagen is now at the Department of Psychology, St. John's University, Grand Central and Utopia Parkways, Jamaica, New York 11439. Reprint requests should be directed to Carolyn Rovee-Collier, Department of Psychology, Busch Campus, Rutgers University, New Brunswick, New Jersey 08903 . predators with keen eyesight (e.g., carnivorous birds such as hawks). Since these predators typically wound their victims during capture and kill and eat them immediately, either on the spot or at a nearby station (Storer, 1971), death feigning would offer few survival opportunities. In contrast, early visual detection is relatively unavailable as a defense against capture at night, and so death feigning might be more likely to be elicited. Since many nocturnal predators are central-place foragers that engage in extensive prey handling and often delay feeding (Curio, 1976; Orians \& Pearson, 1979), nocturnal death feigning could facilitate survival.

There are few systematic field observations of interactions of avians with their nocturnal predators, but these have been consistent with Aschoff's hypothesis. For example, red foxes, which are $90 \%$ nocturnal (Kavanau \& Ramos, 1975), were observed to wait until dark to attack prairie ducks that had been introduced into their pens during the day (Sargeant \& Eberhardt, 1975). Of 50 ducks seen to death-feign during an attack, 29 were subsequently located, and all were unharmed. In laboratory simulations of predation, death-feigning durations are typically 1-2 log units longer at night than in the day (Hennig \& Dunlap, 1977; Rovee, Kaufman, Collier, \& Kent, 1976; Ternes, 1977).

If death feigning constitutes a prey's "last chance" for survival, then it should be relatively resistant to habituation. Moreover, if death feigning confers a selective advantage against nocturnal predators, then it should be most persistent at night. However, past studies of death-feigning habituation have yielded discrepant findings, ranging from 
no habituation (Prestrude \& Crawford, 1970; Eyer, Note 1), or habituation only after prolonged training (Gilman, Marcuse, \& Moore, 1950), to rapid habituation (Nash, 1978) or even response sensitization over repeated trials (Nash \& Gallup, 1976). Because the preceding studies were conducted without regard to the test hour and, with few exceptions (Gilman et al., 1950; Ratner \& Thompson, 1960), involved multiple trials in a single day, it is likely that the changing baseline of response durations, which increase from a trough 1-3 h after light onset to a peak $2-4 \mathrm{~h}$ after dark onset (Rovee et al., 1976), contributed to the discrepancies. Moreover, because the studies involving only a single daily trial were conducted exclusively during the daylight hours, the relative persistence of nocturnal death feigning is not known.

In the following four experiments, we assessed the persistence of nocturnal death feigning by young avians. In view of its hypothesized advantages, nocturnal death feigning was expected to be less plastic than diurnal death feigning. Because the habituation of diurnal death feigning is stimulus specific (Gilman et al., 1950), this aspect of nocturnal habituation was also explored.

\section{EXPERIMENT 1}

In the first experiment, chicks were tested during single daily trials for 8 days, beginning at the age when death feigning can first be elicited with a ventral induction procedure (Posthatch Day 3). Because growing chicks exhibit progressively lengthier durations over this period (Rovee \& Kleinman, 1974), either no change or a decrease in response durations could be taken as evidence of habituation. The question of selective habituation was addressed by testing chicks either during the day or at night, at times when the difference in the duration of response was greatest and the variability in duration was least (Rovee et al., 1976). The specificity of habituation was assessed by introducing a novel experimenter (simulating the predator) on the day after the last habituation trial.

\section{Method}

Subjects. The subjects were 24 White Leghorn chicks (Gallus gallus), drawn randomly from a larger group of 48 chicks which were obtained at 19 days incubation from a local hatchery and dark-hatched in open-window incubators. Following hatching, all chicks were weighed, banded, and equally distributed into two identical environmentally controlled rearing boxes during the light portion of a 12-h photoperiod. Rearing boxes were differentiated only by their designation as either the "day-test" or the "night-test" box. On Day 3 posthatch, the first 12 chicks in each rearing box to exhibit death feigning at the appropriate test hour constituted the experimental group for their respective time period. To form the test groups, we sampled 20 chicks from the day-test box; the first 12 chicks drawn from the night-test box exhibited the response.
Apparatus. Housing was provided in two $91.4 \times 45.7 \times$ $25.4 \mathrm{~cm}$ aluminum starter cages, each of which was located within an insulated and ventilated environmental chamber maintained at a constant temperature of $27^{\circ} \mathrm{C}$. Medicated F.C.A. chick starter and water were continuously available. Rearing boxes were illuminated on a LD 12:12 schedule, with light onset at 0800 h. During light phases, a $60-\mathrm{W}$ bulb produced an intensity range of $40-580 \mathrm{~lx}$.

Death feigning was induced in an adjacent room. The automated test chambers have been described in detail elsewhere (Rovee, Chiapparelli, \& Kaufman, 1977). A 7-W bulb recessed into the top of the test box yielded the minimum amount of light necessary to permit the experimenter to monitor the chick via a one-way glass peephole. Illumination at the level of the test arena was too dim to permit a reading on the light meter (i.e., less than $1 \mathrm{fc}$ ).

Procedure. Beginning on Day 3 posthatch and continuing through Day 10 , each chick received one daily death-feigning trial at either $0900-1100 \mathrm{~h}$ or $2200-2400 \mathrm{~h}$ by one of two trained experimenters, respectively. On Day 11 , the experimenters exchanged test hours in order to assess the extent of generalized habituation to a novel predator.

Death feigning was induced by restraining the chick in a ventral position (cf. Rovee \& Luciano, 1973) for $15 \mathrm{sec}$ beneath an infrared photobeam. Timing of the response began when the experimenter's hand interrupted the photobeam following release of the chick and ended either when the chick stood upright or $2 \mathrm{~h}$ later, whichever came first. Chicks were placed in a communal holding box after testing, and all were returned to the rearing box at once. Dark-tested chicks were maintained in the dark except during testing.

\section{Results and Discussion}

Because the durations were skewed, a logarithmic transformation was performed prior to a twoway analysis of variance over factors of test hour (2) and trials (9), with repeated measures over trials. Although chicks tested nocturnally had significantly lengthier durations than those tested in the light phase $[F(1,22)=58.22, p<.0001]$, the considerable length of the nocturnal durations and the high initial incidence of nocturnal death feigning were unexpected on the basis of earlier research with 3day-old chicks tested exclusively in the light phase (Rovee \& Kleinman, 1974; Rovee-Collier, Kaufman, \& Farina, 1980). Death-feigning durations declined over repeated trials $[F(8,176)=24.03, p<.0001]$, but did so differentially as a function of test hour $[F(8,176)=7.05, p<.0001]$ (see Figure 1).

To ascertain whether the greater persistence of nocturnal death feigning was solely attributable to a greater initial response magnitude, the durations of individual chicks on each trial were divided by the chick's own Trial 1 duration to yield relative response durations (see Figure 2). These scores were converted to $\log$ units and analyzed as before. Once again, chicks tested during the dark phase had longer durations $[F(1,22)=30.90, p<.001]$, and responding declined significantly over trials $[F(7,154)=$ $31.40, p<.001]$. In spite of the elimination of initial differences in responding, the test hour $x$ trials interaction was significant $[F(7,154)=5.23$, $p<$ .001 , indicating that nocturnal death feigning is 


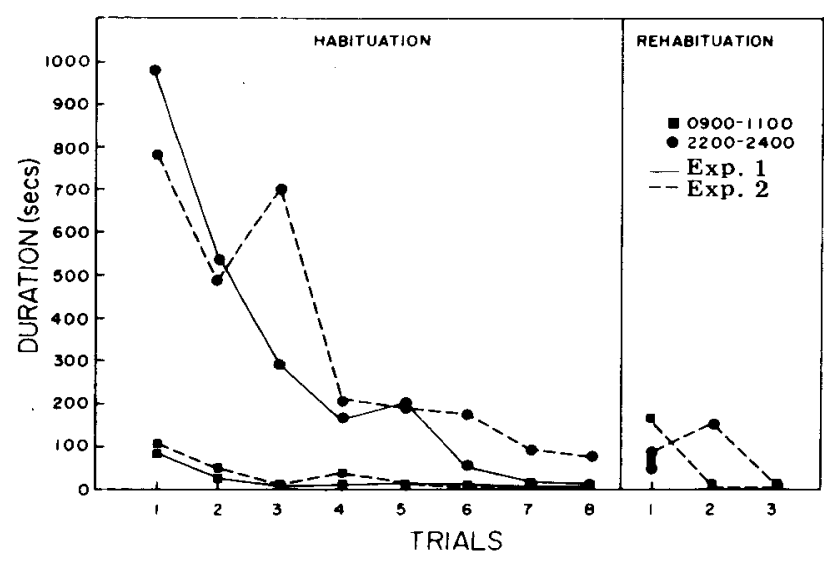

Figure 1. Antilogs (seconds) of mean $\log$ durations of death feigning over successive daily trials administered at either 0900 1100 h (day test) or $2200-2400$ h (night test) in two experiments. Either a generalization test (rehabituation: Trial 1, Experiment 1) or a generalization test plus a rehabituation series (Experiment 2) followed the habituation series.

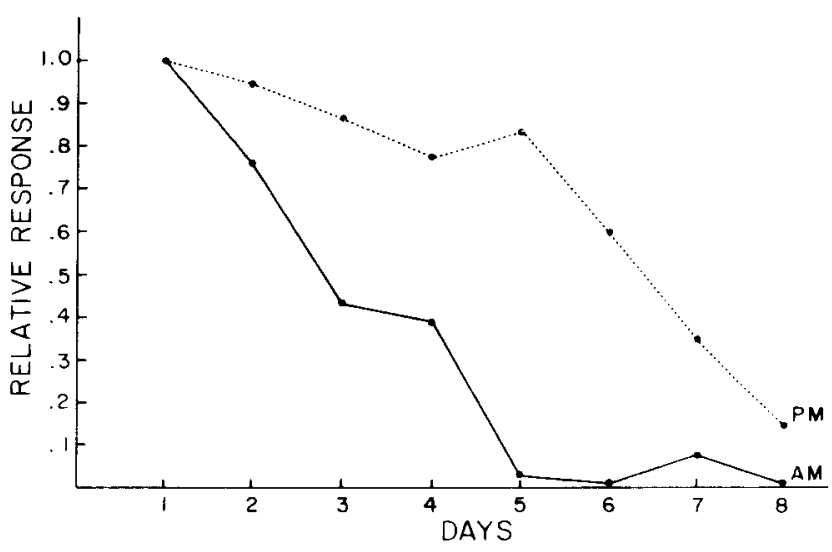

Figure 2. The mean proportion of their initial response durations that chicks tested in the day (AM) or at night (PM) exhibited over successive daily trials (Experiment 1).

less susceptible to modification by prior predation experience than is death feigning elicited during the morning hours. During the habituation series, the two groups differed reliably for the first time on Trial $3[\mathrm{~F}(1,149)=11.71, \mathrm{p}<.001]$ and continued to differ on all succeeding trials. When a novel predator was introduced on the day following the final habituation trial (Rehabituation Trial 1, Figure 1), every chick in both test groups showed an increase in the absolute duration of death feigning relative to the duration on the final habituation trial. This trend was confirmed in the trend analysis of relative responses, which yielded significant linear and quadratic components for day ( $F s=134.43$ and 18.17) and night ( $F s=86.48$ and 8.73) test groups (for all, $\mathrm{df}=1,154, \mathrm{p}<.001$ ).

\section{EXPERIMENT 2}

While the absolute recovery level of the two test groups in Experiment 1 did not differ, their relative recovery levels did. The "completeness" of recovery in only the day-tested chicks could be viewed as evidence of greater stimulus specificity in the daytest group, perhaps resulting from a combined contribution of visual and tactile (handling) cues. At night, visual cues would not be expected to play as great a role. On the other hand, the relatively lower level of recovery of nocturnal death feigning could reflect the particular handling characteristics of the individual who had previously served as the experimenter in the habituation series during the day. Although differences in predator efficacy must surely occur in nature, this was not the original focus of Experiment 1. The second experiment, therefore, replicated the procedure except that for both test groups one experimenter conducted the habituation trials and a second experimenter performed the generalization trials. In addition, the generalization trials were extended to assess whether rehabituation occurred selectively as a function of test hour.

\section{Method}

Subjects. The subjects were 18 White Leghorn chicks, 9 per test hour, obtained from a batch of $\mathbf{3 0}$ dark-hatched in the laboratory and distributed into rearing boxes as in Experiment 1. All chicks tested between 2200 and $2400 \mathrm{~h}$ on Posthatch Day 3 exhibited death feigning; however, it was necessary to test 13 chicks between 0900 and $1100 \mathrm{~h}$ to complete that condition.

Procedure. Test conditions were identical to those of Experiment 1 except that chicks received three rehabituation trials (one per day) and the experimenter within each phase of the study (habituation, rehabituation) did not vary between groups.

\section{Results and Discussion}

As in Experiment 1, death-feigning durations were longer at night than in the day $[F(1,16)=11.88$, $\mathrm{p}<.003]$ and decreased over successive trials $[\mathrm{F}(8,128)$ $=3.18, \mathrm{p}<.003]$ (see Figure 1, left panel). Again, however, habituation proceeded more slowly at night $[F(8,128)=2.10, p<.04]$. During the generalization test, every chick in both groups increased the duration of responding relative to that of the final habituation trial. However, the absolute level of renewed responding did not differ between groups $(t<1.00)$ and was characteristic of the prehabituation response level of the diurnally tested chicks. Rehabituation to the novel predator was rapid and nondifferentiated with respect to test hour.

These data confirm the persistence of nocturnal death feigning found in Experiment 1, and demonstrate that the relatively brief durations exhibited by nocturnally tested birds during the generalization test were not an artifact of the handling characteristics of a particular experimenter. 


\section{EXPERIMENT 3}

In spite of the fact that nocturnally induced death feigning did habituate over an 8-day period in the first two studies, significantly more chicks tested nocturnally continued to respond with durations in excess of $60 \mathrm{sec}$ on the final habituation trial than did diurnally tested chicks $\left[\chi^{2}(1)=10.56, \mathrm{p}<.01\right]$. Because many previous studies of diurnal death feigning have used a 60 -sec habituation criterion rather than a fixed number of trials (e.g., Nash \& Gallup, 1976), we asked, in Experiment 3, how many trials would be necessary for chicks tested nocturnally to attain that habituation criterion. In addition, we sought to determine the extent to which visual novelty contributed to the response recovery observed in Experiments 1 and 2 during the nocturnal generalization test administered following habituation by altering only the visual cues associated with the predator.

\section{Method}

Subjects. The subjects were 10 White Leghorn chicks tested for the first time on the 3rd posthatch day. All animals exhibited death feigning when first drawn from the rearing box. One chick died on the 19th day of the experiment from factors unrelated to testing. Its data were excluded from the analysis of response durations but were included in the figure depicting the percentage of chicks continuing to respond in excess of $60 \mathrm{sec}$ (Figure 3).

Procedure. Maintenance and induction procedures were identical to those of the preceding study except that testing began $4 \mathrm{~h}$ into the dark phase. Each chick received a single daily trial until response duration was $60 \mathrm{sec}$ or less for 2 consecutive days, after which daily trials were administered by the same experimenter (handling cues unchanged), now disguised to appear visually novel. Rehabituation trials were continued until the original response criterion was again attained.

If a chick failed to respond in excess of $60 \mathrm{sec}$ on the initial

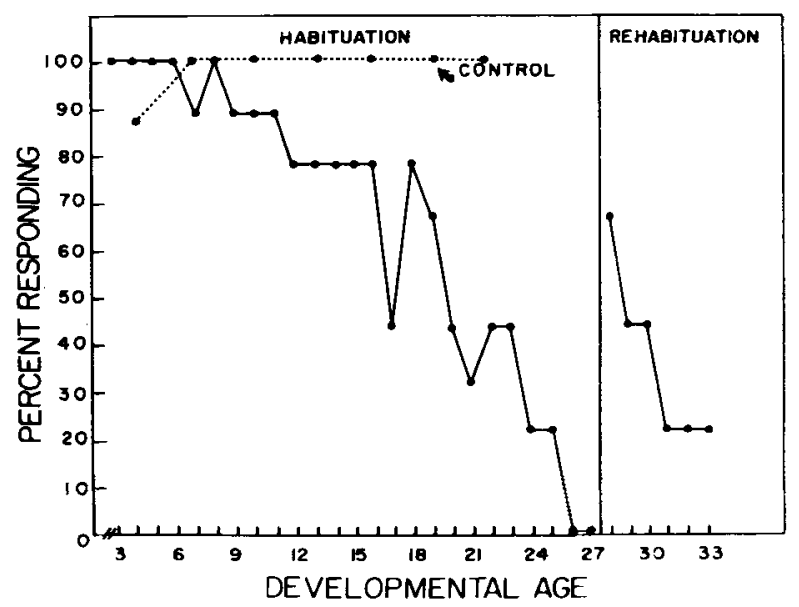

Figure 3. The percentage of night-tested chicks responding in excess of 60 sec during habituation and rehabituation series (Experiment 3, solid lines) or during one-time tests of independent groups at 4, 7, 10, 13, 16, 19, and 22 days of age (Experiment 4, dotted lines). generalization trial, a second induction was attempted after a 1-min delay. If this attempt also failed, a different experimenter was introduced after a $15-\mathrm{min}$ delay and continued to test that chick on subsequent days.

\section{Results and Discussion}

As shown in Figure 3, 80\% of the chicks continued to respond in excess of $60 \mathrm{sec}$ for more than 2 weeks, and only after 25 days of consecutive testing did all chicks meet the habituation criterion (mean $=22$ trials). The incidence of renewed responding in excess of criterion was surprisingly high when just the visual characteristics of the experimenter were changed ( 6 of 9 chicks), and 2 of the 3 remaining chicks renewed responding when a new experimenter was introduced. Thus, chicks responded differentially to a familiar and a novel "predator" and continued to do so with decreasing incidence over succeeding encounters.

For the analysis of response durations, each chick's mean criterion duration was assigned to the remaining habituation trials, during which other chicks continued to be tested. In spite of the fact that this procedure undoubtedly inflated durations relative to those which would have been obtained had the chicks continued to be tested until all had met criterion, a one-way repeated measures analysis of variance confirmed that log durations declined over trials $[F(30,248)=7.66, p<.0001]$ (see Figure 4). A trend analysis over the final six habituation trials and the six rehabituation trials yielded a signif icant cubic component $[F(1,96)=4.18, p<.05]$, indicating that log durations increased significantly during the initial generalization test ("Rehabituation" Trial 1, Figure 4) and then declined over subsequent trials with the "novel" predator. Linear and quadratic components were not significant. As in Experiments 1 and 2, durations during the generalization test were of a magnitude characteristic of day-tested chicks.

\section{EXPERIMENT 4}

Although previous data had shown that deathfeigning durations of chicks reared in continuous light lengthened with age (Rovee \& Kleinman, 1974), the possibility remained that the developmental function for chicks reared on a 12-h photoperiod and tested during the dark phase was different. In this final study, therefore, a developmental function for nocturnal death feigning was obtained from independent groups of chicks tested only once at each of seven ages spanning the period in which chicks were repeatedly tested in Experiment 3.

\section{Method}

Subjects and Procedure. One hundred and twenty-five White Leghorn chicks were obtained on the day of hatch and reared 


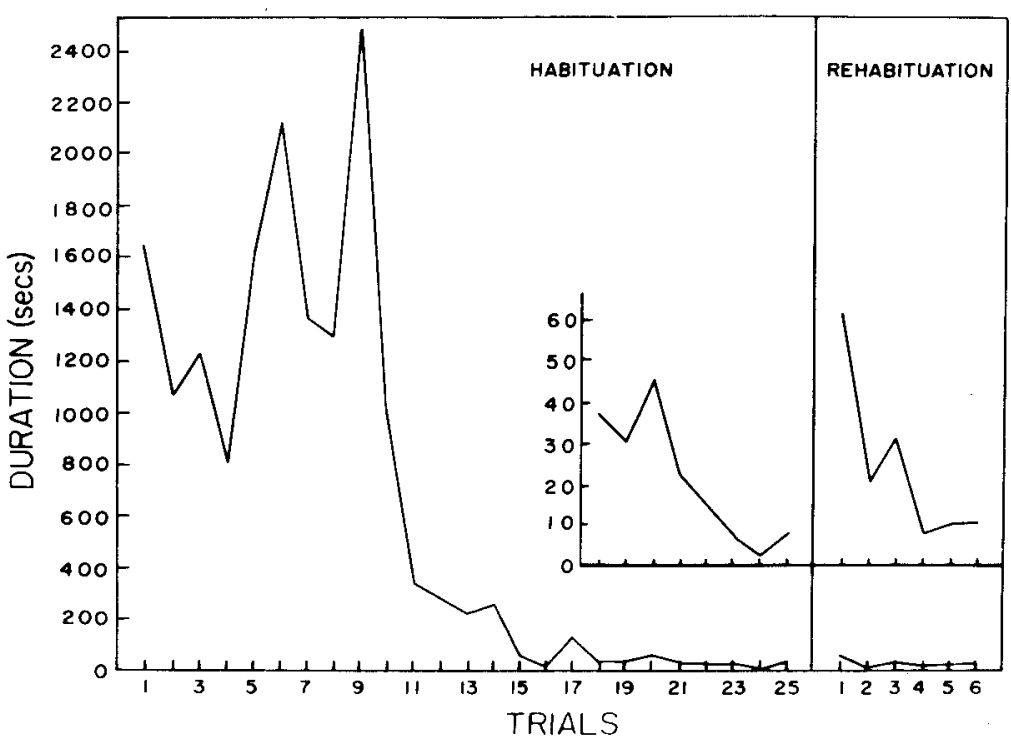

Figure 4. Antilogs (seconds) of mean $\log$ durations of night-tested chicks tested repeatedly during habituation and rehabituation series to criterion of two successive trials with a duration of $60 \mathrm{sec}$ or less. The insert magnified the function during the final 2 weeks of the experiment (Experiment 3).

as before. Beginning on Day 4 posthatch, and on every 3rd day through Day 22 posthatch, 15 chicks were drawn randomly without replacement from the rearing cage between 2200 and $2400 \mathrm{~h}$ for a one-time nocturnal death-feigning test, administered as before. To eliminate the possibility of response effects due to vi-

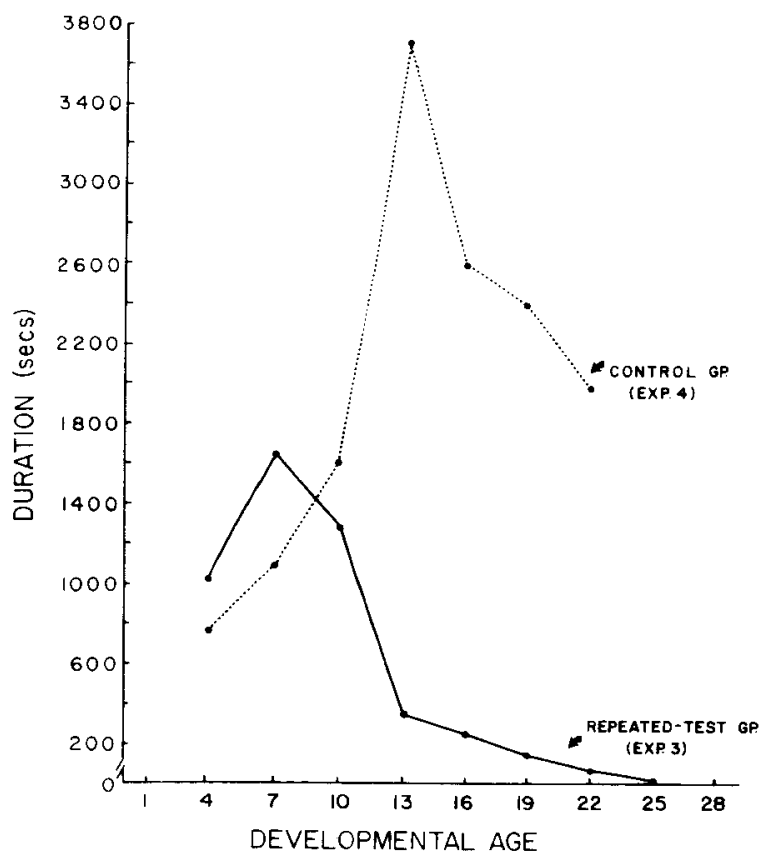

Figure 5. Antilogs (seconds) of mean log durations of independent groups of 15 chicks (Experiment 4, dotted line) tested once only at $4,7,10,13,16,19$, or 22 days of age. The habituation data for corresponding test days are also presented (Experiment 3, solid line). Experiment 3, the first trial was administered at 3 days of age. sual familiarization with the experimenter (cf. Boice \& Williams, 1971; McKnight, Copperberg, \& Ginter, 1978), water and food were replenished in the dark.

\section{Results and Discussion}

A one-way analysis of variance performed over log durations yielded a significant effect of age $[F(6,98)=7.92, p<.0001]$ (see Figure 5). Durations increased linearly until the end of the 2nd week (Day 13) $[F(1,98)=25.65, \mathrm{p}<.001]$, at which time they became shorter [quadratic component: $F(1,98)$ $=18.46, p<.001]$. Durations fell into three statistically distinct clusters (Duncan's multiple range test, $p=.05$ ), being briefest for chicks less than 1 week old (4 days), intermediate for chicks tested in the 2nd week (7-10 days), and lengthiest for chicks 13 days and older. At all but the youngest age, $100 \%$ of the chicks responded in excess of $60 \mathrm{sec}$ (see Figure 3), indicating that the habituation function was not a result of a declining efficacy in the ventral induction method per se.

Comparing functions from single (Experiment 4) and repeated (Experiment 3 ) tests of nocturnal death feigning (Figure 5), we see that death-feigning duration is severely affected by repeated elicitations, even at the rate of only one trial per day. In spite of daily elicitations, however, chicks in Experiment 3 actually responded in the "normal" range until after the 10th posthatch day (i.e., eight habituation trials).

\section{GENERAL DISCUSSION}

Given the importance of death feigning as an unlearned defensive behavior, the fact that it habit- 
uates at all presents an enigma (see also Hinde, 1954, 1960; Melzack, 1961). Moreover, the fact that this behavior wanes more rapidly during the day than at night demands a closer examination of factors which may contribute to this selective decline.

The niche to which a species is adapted is largely determined by food availability (including competition for resources) and predation pressure (Hutchinson, 1959). While the visual physiology of those who prey upon avians nocturnally permits predatory activity over a wide range of illuminances (Kavanau \& Ramos, 1975), the visual physiology of most avians (with a few notable exceptions) is specialized for diurnal feeding. In addition to a large preponderance of cones, the eyes of birds such as pigeons and chickens are flat and set laterally, commanding a 300-deg visual field (Kare \& Rogers, 1976). Thus, avians are well equipped to gather visual information about the presence and movements of potential predators during the day; vigilance (or early detection), mobbing, freezing, and/or flight to a protected area constitute their main lines of defense (Curio, 1976).

Because food gathering and other critical activities of avians are severely constrained by the amount of available light, the most efficient diurnal defenses are those that minimize the disruption of other, ongoing survival-related activities. The prominent defense of most diurnal animals, including avians, is vigilance, which is shared by members of the social group, thus minimizing the amount of time allocated by any single individual to predation defense. It is highly resistant to habituation during the daylight hours and continues to be exhibited even after habituation of other defensive behaviors has occurred (Melzack, 1961; Mueller, 1976; Nestor, Note 2). In contrast, other diurnal defenses are more costly in terms of time and/or energy and habituate with surprising rapidity (Hinde, 1954; Melzack, Penick, \& Beckett, 1959; Mueller, 1976; Schleidt, 1961). This selective habituation of some, but not all, defensive behaviors during the day favors the execution of other survival-related activities that are necessarily relegated to the light phase.

At night, however, the visual cues that contribute to the "early warning system" are unavailable, as is the protection afforded by group defenses during the day. In a state of negative energy balance and functionally isolated from the social group at night, these avians become sedentary. Roosting on tree branches or in low bushes, they are quite literally "sitting ducks" for nocturnal predators. The sustained mouthing by these predators while they are restraining, gripping, or transporting their captured prey is an adequate stimulus for death-feigning induction. Thus, at night there are few defensive alternatives to death feigning, there are few (if any) alternative activities with which extended death feigning would interfere, and the duration of death feigning, which is subject to selective breeding (Gallup, 1974b), is lengthiest at this time (Rovee et al., 1976). The extraordinary resistance to habituation of nocturnally induced death feigning combined with the rapid waning of diurnally induced death feigning, demonstrated in the present series of studies, makes adaptive "sense" and provides strong support for Aschoff's (1964) hypothesis of synchrony in predator-prey relations.

The present data contribute one more instance to the growing list of biological constraints on learning. Habituation has been described as one of the simplest forms of (nonassociative) learning (Buss, 1973; Thorpe, 1963). We have demonstrated here that a basic defensive behavior habituates differentially at two times of the day. Moreover, the selectivity of habituation is consistent with differences in the functional significance of the behavior at these two times.

In addition, the selective habituation of death feigning may have implications for the acquisition of other behaviors. Bolles $(1970,1973)$ has cautioned that data from laboratory procedures which involve the elicitation of species-specific defense reactions (SSDRs) must be interpreted with reference to the biological significance of the behavior for the organism. If the response required by the experimenter competes with a natural SSDR, then learning may occur only gradually, if at all. If the required response is compatible with a natural SSDR, then learning may be rapid. Generalizing from the present findings to studies of associative learning, we would expect that a given SSDR would be more incompatible (or more compatible) with the experimenter-designated response at some times of the day than at others, depending upon the biological advantage afforded by the SSDR at those times. For example, freezing by rats is incompatible with the acquisition of a barpress avoidance response during the day (D'Amato \& Schiff, 1964), but the same response could possibly be learned at night, when rats typically display more active forms of predation defense (cf. Sandman, Kastin, \& Schally, 1971 ) and freezing is less prominent. Thus, the selective association principle (Bolles, 1973) may be even more selective than was originally envisioned.

\section{REFERENCE NOTES}

1. Eyer, J. C. The effects of conspecific vocalizations and repeated testing on the duration of tonic immobility in bobwhite quail (Colinus virginianus). Paper presented at the meeting of the Midwestern Psychological Association, May 1972.

2. Nestor, C. Malnutrition in chicks and its effect on incidental or advantageous learning. Senior honor's thesis, Douglass College, Rutgers University, New Brunswick, N.J., 1981. 


\section{REFERENCES}

Aschoff, J. Survival value of diurnal rhythms. Symposium of the Zoological Society of London, 1964, 13, 79-98.

Boice, R., \& Williams, R. C. Delay in onset of tonic immobility in Rana pipiens. Copeia, 1971, 4, 747-748.

Bolles, R. C. Species-specific defense reactions and avoidance learning. Psychological Review, 1970, 77, 32-48.

Bolles, R. C. The comparative psychology of learning: The selective association principle and some problems with "general" laws of learning. In G. Bermant (Ed.), Perspectives on animal behavior. Glenview, Ill: Scott, Foresman, 1973.

Buss, A. H. Psychology: Man in perspective. New York: Wiley, 1973.

Cur1o, E. The ethology of predation. New York: Springer, 1976.

D'Aмато, M. R., \& Schiff, D. Long-term discriminated avoidance performance in the rat. Journal of Comparative and Physiological Psychology, 1964, 57, 123-126.

Edmunds, M. Defence in animals. Harlow, Essex, England: Longman Group, 1974.

Gallup, G. G., Jr. Animal hypnosis: Factual status of a fictional concept. Psychological Bulletin, 1974, 81, 836-853. (a)

GallUP, G. G., JR. Genetic influence on tonic immobility in chickens. Animal Learning \& Behavior, 1974, 2, 145-147. (b)

Gallup, G. G., JR. Tonic immobility: The role of fear and predation. Psychological Record, 1977, 24, 41-61.

Gilman, T. T., Marcuse, F. L., \& Moore, A. U. Animal hypnosis: A study in the induction of tonic immobility in chickens. Journal of Comparative and Physiological Psychology, 1950, 43, 99-111.

Hennig, C. W., \& Dunlap, W. P. Circadian rhythms and the effect of lighting on tonic immobility in two species of lizards (Anolis carolinensis and Hemidactylus turcicus). Behavioral Biology, 1977, 20, 523-528.

Hinde, R. A. Factors governing the changes in strength of a partially inborn response, as shown by the mobbing behavior of the chaffinch (Fringilla coelebs). II. The waning of the response. Proceedings of the Royal Society (Series B), 1954, 142, 306-341.

Hinde, R. A. Factors governing the changes in strength of a partially inborn response, as shown by the mobbing behavior of the chaffinch (Fringilla coelebs). Proceedings of the Royal Society (Series B), 1960, 753, 398-420.

Hutchinson, G. F. Homage to Santa Rosalia or why there are so many kinds of animals. American Naturalist, 1959, 93, 145-149.

KAre, M. R., \& Rogers, J. G., JR. Sense organs. In P. D. Sturkie (Ed.), A vian physiology (3rd ed.). New York: Springer, 1976.

KavanAU, J. L., \& RAMOs, J. Influences of light on activity and phasing of carnivores. A merican Naturalist, 1975, 109, 391-418.

McKnight, R. R., Copperberg, G. F., \& Ginter, E. J. Duration of tonic immobility in lizards (Anolis carolinensis) as a function of repeated immobilization, frequent handling, and laboratory maintenance. Psychological Record, 1978, 28, 549-556.

Melzack, $\mathbf{R}$. On survival of mallard ducks after "habituation" to the hawk-shaped figure. Behaviour, 1961, 17, 9-16.

Melzack, R., Penick, E., \& Beckett, A. The problem of "innate fear" of the hawk shape: An experimental study with mal. lard ducks. Journal of Comparative and Physiological Psychology, 1959, 52, 694-698.
Muelle R, H. C. Reactions of quail to flying vultures. The Condor, 1976, 78, 120-121.

NAsH, R. F. Habituation and tonic immobility in chickens: Strain comparisons. The Psychological Record, 1978, 28, 109-114.

NAsh, R. F., \& GalluP, G. G., JR. Habituation and tonic immobility in domestic chickens. Journal of Comparative \& Physiological Psychology, 1976, 90, 870-876.

Orians, G. H., \& Pearson, N. E. On the theory of central place foraging. In D. J. Horn, G. R. Stairs, \& R. D. Mitchell (Eds.), Analysis of ecological systems. Columbus: Ohio State University Press, 1979.

Prestrude, A. M., \& Crawford, F. T. Tonic immobility in the lizard, Iguana iguana. Animal Behaviour, 1970, 18, 391-395.

RATNER, S. C. Comparative aspects of hypnosis. In J. E. Gordon (Ed.), Handbook of clinical and experimental hypnosis. New York: Macmillan, 1967.

Ratner, S. C. Animal's defenses: Fighting in predator-prey relations. In P. Pliner, L. Krames, \& T. Alloway (Eds.), Advances in the study of communication and affect. (Vol. 2): Nonverbal communication of aggression. New York: Plenum Press, 1975.

RAtner, S. C., \& Thompson, R. W. Immobility reactions (fear) of domestic fowl as a function of age and prior experience. Animal Behaviour, 1960, 8, 186-191.

Rovee, C. K., Chiapparelli, W. J., \& Kaufman, L. W. The influence of altered lighting regimes on the periodicity of death feigning. Physiology \& Behavior, 1977, 18, 179-182.

Rovee, C. K., Kautman, L. W., Collier, G. H., \& Kent, G. C., $\mathrm{J}_{\mathrm{R}}$. Periodicity of death feigning by domestic fowl in response to simulated predation. Physiology \& Behavior, 1976, 17, 891-895.

Rovee, C. K., \& Kleinman, J. M. Developmental changes in tonic immobility in young chicks (Gallus gallus). Developmental Psychobiology, 1974, 7, 71-77.

Rovee, C. K., \& Luciano, D. P. Rearing influences on tonic immobility in three-day-old chicks (Gallus gallus). Journal of Comparative and Physiological Psychology, 1973, 83, 351-354.

Rovee-Collien, C., Kaufman, L. W., \& Farina, P. The critical cues for diurnal death feigning in young chicks: A functional analysis. American Journal of Psychology, 1980, 93, 259-268.

Sandman, C. A., Kastin, A. J., \& Schally, A. V. Behavioral inhibition as modified by melanocyte-stimulating hormone (MSH) and light-dark conditions. Physiology \& Behavior, 1971, 6, 45-48.

Saraeant, A. B., \& Eberhardt, L. E. Death feigning by ducks in response to predation by red foxes (Vulpes fulva). American Midland Naturalist, 1975, 94, 108-119.

SchleIDT, W. Über die Auslosung der Flucht vor Raubvogein bei Truthahn. Naturwissenschaften, 1961, 48, 141-142.

Storer, R. W. Adaptive radiation of birds. In D. S. Farner \& J. R. King (Eds.), A vian biology (Vol. 1). New York: Academic Press, 1971.

Tennes, J. W. Circadian susceptibility to animal hypnosis. Psychological Record, 1977, 27, 15-19.

ThORPE, W. H. Learning and instinct in animals (2nd ed.). London: Methusen, 1963.

(Manuscript received May 29, 1981 ; revision accepted for publication October 6, 1982.) 